\title{
Gözetim Toplumunun Siyaset, Devlet ve Demokraside Yansımaları: Algoritmik Vatandaşlık Odağında Bir Değerlendirme
}

\author{
Ümmühan KAYGISIZ1
}

$\ddot{O} z$

Gözetim toplumu kendisinden önceki her toplumsal yapı gibi kendisine has bazı spesifik özellikleri ile birlikte giderek yoğunlaşmaktadır. Toplumlar tarım ve sanayiden sonra bilgi toplumuna geçmekle kolay takip edilemeyen boyutta hızlı gelişmeleri de beraberinde yaşamışlardır. Bu baş döndürücü hızda yeni nesil teknolojiler öncü rol oynamıştır. Gözetim toplumu var olan devlet ve toplum temalarını tamamen ortadan kaldırmamıs ancak bambaşka boyutlar kazandırmıştır. Bu yeni toplum modelinin siyaset ve devlet yapısında meydana getirdiği farklılaşmalar demokrasi üzerinde de önemli etkiler oluşturmuştur. Demokratik araçlar üzerinde pozitif fark yarattı̆̆ alanlar olmakla birlikte önemli demokratik değerlerin sorgulanmasına da yol açmıştır. Demokrasinin en önemli sürücüsü olan vatandaş kavramı farklılaşarak algoritmik vatandaşlık kavramı sorgulanır olmuştur. Jus algoritmi ya da algoritmik vatandaşlık, bir çeşit veri tabanlı bir vatandaşlık versiyonudur. Jus algoritmi, gözetim toplumu ile birlikte ortaya çıkan daha çok geleneksel vatandaşlık modellerinden farklı olarak bireysel seçim hakkına dayanan bir vatandaşlıktır. Çalışmada geniş literatür incelemesi yapılmıştır. Jus algoritmi hakkında bilgiler vererek gözetim toplumunun devlet, siyaset ve demokrasideki yansımalarının değerlendirilmesi amaçlanmaktadır.

Anahtar Kelimeler: Siyaset, Algoritmik Vatandaşlık, Devlet, Demokrasi, Gözetim Toplumu.

\section{The Reflections of the Surveillance Society on Politics, State and Democracy: An}

\section{Assessment in the Focus of Algorithmic Citizenship}

\section{Abstract}

The surveillance society is increasingly concentrated, along with its specific characteristics, like any social structure before it. After the agriculture and industry, societies have experienced rapid developments that cannot be easily followed by the transition to an information society. At this dizzying speed, new generation technologies played a leading role. The surveillance society does not completely eliminate the existing state and society themes, but has brought a whole new dimension. The differentiations of this new society model in politics and the state structure have also had important effects on democracy. While it has areas where it makes a positive difference on democratic instruments, it also leads to questioning of important democratic values. The concept of citizenship, which is the most important driver of democracy, has been differentiated and the concept of algorithmic citizenship has been questioned. Jus algorithm or algorithmic citizenship is a kind of data-based citizenship. Jus algorithm is a citizenship based on individual choice, unlike the more traditional citizenship models that emerged with the surveillance society. A large literature review was conducted in the study. It is aimed to evaluate the reflections of the surveillance society on state, politics and democracy by providing information about Jus algorithm.

Key Words: Politics, Algoritmic citizenship, State, Democracy, Surveillence society

\section{Atıf İçin / Please Cite As:}

Kaygısız, Ü. (2020). Gözetim toplumunun siyaset, devlet ve demokraside yansımaları: Algoritmik vatandaşlik odağında bir değerlendirme. Manas Sosyal Araştırmalar Dergisi, 9(2), 1288-1299.

Geliş Tarihi / Received Date: 08.03.2019

Kabul Tarihi / Accepted Date: 20.08.2019

\footnotetext{
${ }^{1}$ Doç. Dr. - Burdur Mehmet Akif Ersoy Üniversitesi, İ̈BF, ukaygisiz@mehmetakif.edu.tr ORCID ID: 0000-0003-0418-0144
} 


\section{Giriş}

Avrupa, 1648 Westfalya Antlaşması'nda sabit toprak bütünlügü ve egemenlik ilkesine karar verilmesiyle ulus devleti meydana getirmiştir. Arendt, vatansızlık kitlesel fenomeninin başlangıcını ulus devletin gerilemesine kadar götürerek millet ve devlet arasında ayrım yapmıştır (Arendt, 1949, s. 20-37). Buna göre, millet, egemen grubun kültürüne, diline ve sınırlı bir bölgede yaşayan ortak tarihine değinirken, devlet ise bir bölgede yaşayan ve yasal haklara sahip vatandaş olarak kabul edilen kişilerden oluşan yasal statüye vurgu yapmaktadır (Bernstein, 2018, s. 15-17). Genel olarak, millet ve devlet olgusu tarihsel olarak bu şekilde devam etmektedir. Ancak yaşanan dönüşümler, inovatif gelişmeler ve daha birçok etken ile birlikte farklılaşmaktadırlar. Aslında toplumlar bir moddan diğerine keskin bir şekilde dönüşmez; aksine, önceki toplumlardaki sosyal unsurlar sürekli değişen şekiller ile devam eder ve çoğalır. Bu bağlamda önceki toplumsal yapıya ait olan bazı unsurlar yeniden üretilmektedir. Öte taraftan tarım, sanayi, bilgi toplumu derken gelinen noktada yeni nesil teknolojilerin etkisiyle bir gözetim toplumu ortaya çıkmıştır. Bahsedildiği gibi gözetim toplumu var olan devlet ve toplum temalarını ortadan kaldırmamış ancak bambaşka şekiller vermiştir. Gözetim çalışmaları, politik güvenlik teknolojisi, güç, kültür, kimlik, eşitsizlik, etik ve direniş, kamusal ve özel mekân, vatandaşlik gibi hassas konularla ilgilenerek günümüzün en önemli sorularından bazılarını ele almaktadır. Bu kapsamda Lefebvre, hayatı ve toplumu değiştirme ilkelerinin, uygun bir alan üretilmeden hiçbir şey ifade etmeyeceğini vurgulamaktadır. Toplumsal dönüşüm neticesinde ortaya çıkan yeni sosyal ilişkiler, yeni bir mekân bazen de bunun tersi şeklinde mekansızlık olarak adlandırılmaktadır (Lefebvre, 1974, s. 59).

Görüldüğü gibi dijital çă̆ ve sonrasında ortaya çıkan gözetim toplumu bir çok hususun yeniden sorgulanmasına yol açmaktadır. Bu toplumsal yapı ile birlikte dönüssen millet, devlet ve toplum eksenli olarak meydana gelen gelişmeler doğal olarak vatandaşlık yapılarına da nüfuz etmiştir. Buna göre ulus devlet vatandaşlğı var olmakla birlikte dünya vatandaşlı̆̆ı, likit vatandaşlık, ulus devletlerin hızla büyümesi ile birlikte metropolitleşme eğiliminden kaynaklanan bir "metropolitan/büyükşehir vatandaşlı̆̆ı" gibi farklı vatandaşlık modelleri de karakterize edilmektedir (Rodriguez-Posé, 2018, s. 189-209). Dijital çağın etkisiyle sosyal, kültürel, siyasal ve ekonomik faaliyetlerin de bu alana taşınmasıyla birlikte ortaya çıan vatandaşlık modeli ise algoritmik vatandaşlık olmuştur.

Algoritmik vatandaşlık tipik olarak, insanların toplumdaki rolünü dijital teknolojiler kullanarak kabul etmesi olarak tanımlanır. Bu nedenle güçlendirici ve demokratikleştirici özelliklere sahiptir. Öte taraftan algoritmik bir vatandaşlık için veri ortamında bir takım gereksinimler vardır. Aynı zamanda hem devlet kurumları hem de internet şirketleri bu vatandaşların faaliyetlerini izlemekte ve güç dengesi buna göre değişmektedir. Gözetim toplumu olarak adlandırılan bu yeni toplum modeli devlet, siyaset, demokrasi ve algoritmik vatandaşlık üzerinde önemli etkiler yapmaktadır.

\section{Gözetim Toplumu}

Sosyal ve siyasal gözetim ve kontrol için yeni teknolojilerin uygulanması yeni bir bakış açısı değildir (Gandy 1994; Lyon 1994; Davies, 1996). Foucault'un toplumdaki disiplin gözetimine dair çalışmas1, gözetimin itaatkâr vatandaşlar oluşturmak için tasarlanan disiplin ağının yeni bir teknolojik aracı olan genel bir güç ifadesi olduğunu ileri sürmektedir. Giddens'in (1985) çalışması, vatandaşların faaliyetlerini düzenlemek için devletin idari gücünü pekiştirmek için yeni teknolojinin uygulanmasına işaret etmektedir. Görüldüğü gibi gözetim uygulamasının vatandaş-devlet ilişkisinin evrimi için temel etkileri vardır. Bunun nedeni, gözetimin sadece yasa ve düzeni sağlamak için bir politika aracı değil aynı zamanda vatandaşları ve toplumu kontrol eden bir araç olmasıdır. Yeni vatandaş-devlet ilişkisi, vatandaşların devlet gözetimini norm olarak kabulü ile karakterizedir. Gözetimin kapsamı, "gözetim toplumu" olarak adlandırılabilecek bir döneme girildiğini net bir şekilde ortaya koymaktadır (Davies 1996; Lyon 1994; Webster, 1999, s. 126-127).

"Gözetim çalışmaları" alanı, gelinen noktada yönetişimdeki hızlı gelişmeler ve ortaya çıkan yeni teknolojilerle birlikte çok hızlı bir şekilde gelişmektedir. Gözetim uygulamaları insanlık tarihi kadar eski olsa da, içinde bulunduğumuz çağda bazı özel şekillere bürünmüştür. Bilgisayar tabanlı olarak yeni teknolojiler gözetim süreçlerinde kararllıkla uygulanmaktadır. Bu alanda Foucault'un Disiplin ve Ceza (Discipline ve Punish, 1979) çalışması, gözetimi anlamak için yeni yaklaşımları teşvik etmiştir. Gözetim Foucault'un eserlerinin çoğunda tema olarak gözükse de, yeni tartısmaların merkezinde yer almaya devam etmektedir (Lyon, 2006, s. 3). Günümüzde gözetim olgusu panoptikon olarak oldukça farklı şekilleriyle 
birlikte yaygınlaşmaya devam etmektedir. Jeremy Bentham'ın açıkça düşündüğü gibi ve Foucault’un bazen ima ettiği gibi gözetimin disiplin gücünü mükemmelleştirdiği fikri bunda etkilidir.

Bilgi ve iletişim teknolojisi (BİT) olarak gözetim teknolojisinin, hukuk devleti kurallarına dayanan kapitalist ulus devletlerin özelliklerinde önemli dönüşümler sağladığı net bir şekilde ortadadır. Modern toplum, bilgi yoğun bir toplumdur, ancak aynı zamanda devletin ve bireylerin modernist ön koşullarını sınırlandırmaktadır. BİT’e dayalı gözetimin gelişmesiyle birlikte, yalnızca mahremiyet ve medeni özgürlük değil, aynı zamanda demokrasi ve kimlik politikaları da dönüşmektedir (Ogura, 2006, s. 270).

Açıllandığı üzere bilgi iletişim teknolojilerinde kalıcı bağlantıya doğru kaymanın farklı boyutları vardır. Harvard Business School'dan Shoshana Zuboff bu durumu "gözetim kapitalizmi" olarak yeni bir kapitalizm aşaması şeklinde değerlendirmektedir. Zuboff a göre, gözetim kapitalizmi, yeni malların ya da kurumların üretilmesinden ziyade, Google gibi yapılanmalarla verilerin çıarılması üzerine belirgin bir vurgu içermektedir (Zuboff, 2015, s. 75). Bu gruplardaki güç yoğunluğu, egemen oldukları veri sektörleri ve bu dönüşümün özgürlük gibi değerler için olumsuz etkilerinden bahsetmektedir (Couldry, 2017, s. 182).

Bu bağlamda gözetim altyapısı sadece genel anlamda özgürlükle değil, bir düzeyde çoğu demokratik yaşam vizyonu için referans noktası sağlayan özerklik kavramı ile tezat oluşturmaktadır (Couldry, 2017, s. 183). Devlet kurumları tarafindan yapılan sistematik kitlesel gözetim ise, satın alma ve tercihlerin, finansal işlemlerin, fiziki konumun, iletişim kuran kişilerin, grupların ve iletişimin içeriğinin izlenmesi ile son derece yoğun olmaktadır. Hatta gelinen noktada gözetimin vatandaşlar üzerinde önemli fayda ve maliyetleri oluşabilmektedir.

Bunun en güncel örneklerinden birisini Çin oluşturmaktadır. Çin, 2020'ye kadar tüm ülkeyi kapsaması beklenen bir sistemle vatandaşlarını izlemek için, yüz tanıma, yapay zekâ, akıllı gözlük ve diğer teknolojileri kullanarak yeni bir sosyal puanlama sistemi getirmektedir. Puanlama sistemi, vatandaşları puanlayacak, buna göre düşük puan alan vatandaşlara çeşitli cezalar uygulanacaktır. Böylelikle, 1.4 milyar nüfuslu Çin'de, düşük puan alanların uçak bileti alması, emlak sahibi olması, yüksek hızlı internet kullanması yasaklanabilecektir. Kamu Güveni Enformasyon Merkezinin yayınladığı son rapora göre, 17,5 milyon insanın uçağa binmesi, 5,5 milyonun tren kullanması ve 128 kişinin ülkeden çıkması engellenmiştir. Öte yandan iyi puanlı vatandaşlar için ise elektrik, gaz ve su faturalarında indirim, depozitosuz çeşitli kiralama hizmetlerinden yararlanma ve sosyal paylaşım sitelerinde daha fazla arkadaş edindirme gibi ödüller bulunmaktadır. Nihai amaç ise, niceliksel önlemlere ve çevrimiçi verilerin toplanmasına atıfta bulunmadan, ceza ve ödül mekanizmalarına dayanan tek biçimli bir sosyal kredi sistemi olarak açıklanmaktadır (Síthigh ve Siems, 2019, s. 13; Chorzempa, Triolo ve Sacks 2018, s. 3; Akos, 2017, s. 52-53). Bu yeni puanlama sisteminin yöntemi, denetlenmesi, kişisel mahremiyet boyutu ve hukuki sonuçları ise geldiğimiz noktada gözetim toplumunun kaygılarını oluşturmaktadır. "Orwellyen sistem" perspektifinde dijital platformlarda gücün hissedilebildiği ancak kesin olarak bilinemeyeceği bir distopya durumunu çağnıştırmaktadır.

Gözetim konusunda, esas önemli olan izleyicinin niyet ve sebep sorunlarıdır. Bütün mahkûmların davranışlarını onlar tarafindan görülmeden izleyen sebep, panoptikon fikrini ortaya çıkarmıştır. Bilinmeyen müşterilerin davranışlarını bilme nedeni, pazarlama için yenilikçi teknolojiyi getirmiş̧ir. Polisin sokaktaki vatandaşları izlemedeki gizli niyeti, vatandaşların tutumlarına, moda alışkanlıklarına, yaşlarına, ırklarına, cinsiyetlerine ve diğer görünümlerine dayanarak suç işleme olasılığını tespit etmektir. Böylelikle ticari sektörden kolluk kuvvetlerine, belirleme isteği yaygınlaşmıştır. Bilinmeyeni belirleme isteği, gözetim teknolojisinin inovasyonu için sosyal arka planı oluşturmuştur. Kimlik belirleme sorunları, mahremiyet ve medeni özgürlük konularıla yakından ilgilidir. Sosyal ilerlemeye dayalı teknoloji, pozitif değerler için tehlikeli özelliklere sahiptir. Dünya geneline bakıldığı zaman bilhassa 11 Eylül sonrası, tespit etme arzusu her zamankinden daha fazla ulusal güvenliğe bağlı hale gelmiştir (Ogura, 2006, s. 271). Gözetim odaklı toplum tarihsel olarak yoğun bir büyüme göstermiştir. İşyerinde davranışların görünmesini ve kontrolünü izlemek kamusal alana genişletilmiştir. Gelinen nokta, gelecekteki davranışları kontrol etmek için içsel olarak izlemek ve insan aklının niyetini analiz etmeye doğru evrilmektedir. Modern kapitalist toplumda gözetimin amacı her bireyi işgücü olarak kontrol etmek ve harekete geçirmek ve çeşitli öz niteliklerin ulusal kimliğe entegre edilmesidir. Içinde bulunduğumuz çağda gözetim teknolojileri öncelikle suçu tespit etmek, caydırmak ve azaltmak için kullanılan bir araçtır. Bununla birlikte, devletin demokratik kurumları tarafindan sağlanan bir politika aracı olarak gözetim, yeni teknoloji ve politika süreçleri arasındaki ilişkileri vurgulamaktadır. Bu süreçler, politik söylem ve halk söylemini birleştirir ve çağdaş demokratik pratik için merkezi öneme sahiptir. 


\section{Gözetim Toplumunda Siyaset, Devlet ve Demokrasi}

Dijital çağ oluşturduğu yeni toplumsal altyapısı ile birlikte teknolojilerin etkileyici bir şekilde kamusal, ticari ve özel bağlamda kitle gözlem ve kontrol ağının oluşturulmasına yardım ederek bir gözetim dünyası ortaya çıkarmıştır. Frederick Taylor'un Amerika Birleşik Devletleri'nde on dokuzuncu yüzyılın sonlarındaki bilimsel yönetim stratejileri, işçilerin davranışlarının gözetimi ile sonuçlanmıştır. Taylor, insan davranışlarını tek bir hareketle oluşturulan parçalara bölerek insan vücudunu kontrol etmeyi amaçlamıştır. Fordizm, Taylor'un fikirlerini insan davranışlarının mekanizasyonuyla devralmışıı. Buradaki söz konusu makinalaştırma yalnızca ekonomik etkililiğin peşinden koşmakla kalmamakta, aynı zamanda çalışanların gözetimini de kastetmektedir (Ogura, 2006, s. 273). Bu durumu, Antonio Gramsci Hapishane Defterleri'nde, kapitalist toplumun insan aklını kontrol edemeyeceği için insan davranışını kontrol etme niyetinde olduğu şeklinde ifade etmektedir (Gramsci, 1984, s. 277-320).

Anthony Giddens gözetim konusunun, yalnızca bir tür kapitalizm refleksi olarak fabrikada çalışanların izlenmesi veya ulus devletin vatandaşlar üzerinde idari kontrolü şeklinde değil kendi içinde bir güçlendirici olarak değerlendirilmesini savunmaktadır (Giddens, 1985, s. 41). Gözetim olgusunda öne çikan, Marksist ve Weberyen gelenekle yapılan çalışmalar incelendiğinde, Karl Marx'in, emek ve sermaye arasındaki mücadelenin bir yönü olarak gözetime özel önem verdiği görülmektedir. Zira işçileri denetlemek sermaye adına yönetim kontrolünü sağlamanın bir aracı olarak değerlendirilmektedir. Öte yandan, Max Weber tüm modern organizasyonların, bürokraside etkin uygulama arayışının bir parçası olarak, dosya biçiminde veri saklama ve alma yollarını geliştirmelerine odaklanmaktadır. Bu tür dosyalar sıklıkla kişisel bilgiler içerir, böylelikle kuruluşlar, özellikle devlet yöneticileri, topluluklar üzerinde kontrol gerçekleştirebilirler (Lyon, 1994, s. 7). Foucault'un gözetim teorisine katkısı daha da karmaşık olsa da, basitçe modern toplumların, acımasız kamu cezaları gibi geleneksel yöntemlerle etkin bir şekilde toplumu düzenleyen rasyonel araçlar geliştirmesi olarak ifade edilebilir (Lyon, 1994, s. 7).

George Orwell, gözetimin demokratik olmayan yöntemlerle vatandaş üzerinde oluşturabileceği olumsuz baskıyı nasıl uygulayabileceğinin klasik analizini gerçekleştirmiştir. İlk kez 1949'da yayınlanan 1984'te, Orwell, “telescreen” adlı bir makine hayal etmiştir. Bu açık cihaz, propagandayı kesintisiz olarak yayınlamakta ve devlet yetkililerinin "Düşünce Polisi"nin halkı gözlemlemesini sağlamaktadır (Schwartz, 1999, s. 1656-1657). Geldiğimiz çağda bilgisayarlardaki internet aynı gözetimi gerçekleştirmektedir. Yeni teknolojiler vatandaşlara bilgi toplama, geniş çapta dağıtma, seçkinlerin performansını incelemeye alma, yetkilileri ve adayları sorgulama becerisi kazandırmaktadır. O’Toole (1990), Orwellian gözetiminin tahminlerine karşı, totaliter ülkelerde kullanılan bilgi teknolojilerinin "totaliterizmin özel düşmanı" olarak tanımladığ1 çoğulculuğun gelişmesini sağladığına işaret etmektedir (O’toole, 1990, s. 220).

Öte taraftan internet vasitasıyla, sosyal ve kamusal yaşam ile ilgili verilerin toplanması ve böyle bir veri toplamanın dayandığı sürekli otomatik izleme konusu demokratik kurumlar ve değerlerle çelişmektedir. Bireyin kimlik duygusu, yaşam hakkı, insan hakları, mahremiyet gibi konular bu doğrultuda her zamankinden fazla önem arz etmektedir. Siyasi iktidar, sosyal kontrol, özgürlük ve demokrasi gibi konular ise en önemli köşe taşlarıdır. Görüldüğü gibi internetin teknik özelliklerinin olumsuz bir sonucu olarak faaliyetlerin yoğun bir şekilde izlenmesi mümkündür. Siber uzayda bir bireyin faaliyetleri ve davranışları hakkında genellikle izinsiz ve hatta bilgisi olmadan ince bir şekilde ayrıntıll veriler üretilmektedir (Schwartz, 1999, s. 1620). Hatta bu kapsamda toplanan "kötü bilgi", bireylerin sahip olduğu özgürlük ve mahremiyet derecesini sınırlayarak demokratik bir sistemin niteliğini tehdit edebilmektedir. Bireylerin bilgiye erişmesini ve bilgi dağıtmasını sağlayan teknolojiler aynı zamanda kullanıcıları hakkında da bilgi toplayabilmektedir (Harrison ve Falvey, 2001, s. 10). Fakat bilgi endüstrisi her zamankinden daha fazla bilgisayarlar yoluyla veri tabanları, dosyalar, gözetim kameraları ve istihbarat analistleri için ulusal güvenlik önlemleri talep etmektedir. Bu kapsamda gözetim ve veri gözetimi kullanımının genişlemesinin hükümete önemli şekillerde yardımcı olduğu konusunda hiçbir tartışma yoktur. Bilişim teknolojisi devletler için terörle ve diğer güvenlik sorunları ile mücadelenin çok önemli bir parçası haline gelmiştir (O’Harrow, 2005, s. 7).

İçinde bulunduğumuz çağda, ekonomik ve sosyal genişleme için gerekli iletişim altyapısı oluşturulmakla birlikte küreselleşmiş bağlantı ulus-devlet yönetiminin sınırlarını zorlayan çeşitli süreçler üretmeye başlamıştır. İnternetin gelişmesi tarihi, genellikle “özgürlük teknolojisinin” bir genişlemesi olarak anlatılmıştır. Ancak, interneti bir özgürlük teknolojisi olarak görmek temeli özgürlük değil, bağlantı olduğu için çok basit bir bakış açısı olarak kalmaktadır. İnternete erişim hakkı bir özgürlük olarak değerlendirilebileceği gibi diğer yandan tüm bilgi paketleri ve internete erişilen tüm sitelerin gözetim altında olması nedeniyle özgürlükleri sınırlandırıcı etki yapmaktadır (Couldry, 2017, s. 183). 
John Dewey "birleşik iletişim deneyimi" şeklinde demokrasi teorisi oluşturmuştur (Dewey, 1993, s. 110). Buna göre demokrasinin temelini "çok sayıda insanın deneyimlerinin net sonuçlarının birleștirilmesini” sağlayan sosyal bir iletișim biçimi olarak vurgulamaktadır (Dewey, 1993, s. 208). Bu doğrultuda 20. yüzyıldaki demokratik teori yorumlarının çoğu aktif vatandaşı demokratik sistemlerin merkezine yerleştirmiştir (Berelson, 1952, s. 313-314). En saf formuyla siyasal iktidar demokrasilerde vatandașlara aittir (Tewksbury ve Rittenberg, 2012, s. 6). Böylesine bir demokratik ve iyi toplum ideali ise müzakereci demokrasiye dayanmaktadır. Liberalizmin birey üzerindeki vurgusu yerine, bir ülkenin temel politik değerleri vatandaşlar tarafindan oluşturulmalıdır. Güçlü demokrasi, ortak katılımcı faaliyetlere, karşlıklı sayg1 ve siyasi konular hakkında fikir birliğine olan ihtiyaç üzerinde durmaktadır. Bu bağlamda internet elektronik ticaret alanı olarak değil, müzakereci demokrasi için bir forum olarak yer alacaktır. Benjamin Barber'n ifadesiyle "çoğul tabiatları bırakmadan ortak bir şekilde bireyin kendisini yönetebileceği” ortak alanlara yönelik arzuya dayanmaktadır. Bu bağlamda internet sadece gözetim mekânı olarak değil gerçek demokratik söylemlerin eleştirel ve düzeltici zorluklarının ortaya çıkabileceği sivil forumlar için bir alan sağlayabilmektedir. Diğer bir deyişle "demokratik tutumların oluşturulduğu ve demokratik davranışların şartlandırıldığı bir serbest alan” çağrısına cevap verebilmektedir. Öte taraftan internetin demokrasiyi geliştirme potansiyeli, demokratik topluluğun ihtiyaç duyduğu bilgi kullanım türlerini sağlamadıkça sınırlandırılacaktır (Schwartz, 1999, s. 1649-1653). Buradaki asıl soru ise demokrasi, yeni bilgi teknolojilerinin yayılması yoluyla mı ilerlemektedir? Olmaktadır. Son yıllarda, teknolojideki bu denli hızlı gelişmelerin demokratikleşme hususu ile önemli bir nedensellik bağı bulunmaktadır. Yeni bilgi ve iletişim teknolojileri, cep telefonları ve internet gibi yeni altyapı koşulları sağlamış ve siyasal iletişim sistemleri ve demokrasi kurumları için geniş sonuçlar ortaya çıkarmıştır (Howard, 2010, s. 13).

$\mathrm{Bu}$ anlamda bir e-devlet, e-demokrasi arke tipi demokratik gelişmeleri oluşturmakla birlikte bahsedilen gözetim olgusu ile birlikte otoriter yönetim için olası firsatları ortaya çıkarabilmektedir. Böylelikle gözetim teknolojilerindeki gelişmeler, hem demokrasi hem de diktatörlügün çağdaş anlatılarının bir parçası olarak ortaya çıkmaktadır. Diğer bir deyişle teknoloji demokratik geçişlerde rol oynamakta ve de otoriter elitlere firsat vermektedir (Howard, 2010, s. 15-27).

1960'lardan sonra başlayan hızlı büyüme yerleșik kapitalist toplumlarda ve aynı zamanda gelişmekte olan dünyada ortaya çıkardığı çok yönlü değişikliklerle zaman zaman istikrarsızlaştırıcı özellikleri de beraberinde getirmiştir. Böylelikle yerleşik demokrasilerin ekonomik tabanı ile sınırlı kalmayıp aynı zamanda demokrasilerin istikrarlı ve dayanıklı rejimler olarak işlev görmesi gereken sosyal tabana da yayılmıştır. Ortaya çıkan gelişmeler, sosyal hayatı, insanların birbirleriyle ve başkalarıyla iletişim tarzını değiştirmektedir. Dijital sosyal medya, Facebook, Twitter ve YouTube gibi önde gelen örnekler, demokrasiler, demokrasinin toplumsal gereklilikleri ve bunların sosyal temelleri için bazen olumlu bazen de yıkıcı sonuçları olan küresel iletişim kanalları haline gelmiştir. Dijital ortamın demokratik katılımı arttırma yollarından biri, bu teknolojinin potansiyel küresel bağlantısıdır (Lutz ve Toit, 2014, s. 3).

“Dijital Demokrasi”lerde yeni bilgi ve iletişim teknolojileri ile demokratik yapılar ve prosedürler arasında karmaşı ilişkiler ortaya çıkmıştır (Hague ve Loader, 1999, s. 3-4). Dijital çağdaki demokrasi ile ilgili tartışmalar, internet tabanlı uygulamaların gelişmiş demokratik uygulamalar için ve özellikle de vatandaşların demokratik sürece "girdi"sinin geliştirilmesindeki potansiyeline odaklanmaktadır. Dijital teknolojiler ve internet günümüzde demokratik süreçler üzerinde doğrudan etkilidir. Bu teknolojiler doğrudan demokratik prosedürleri geliştirmek üzere tasarlanmış teknolojik bir araç olmaktan ziyade, politika amaçlarını ve hizmet gereksinimlerini karşılamak için kullanılan yoğun politika araçlarıdır (Webster, 1999, s. 118).

"Dijital" veya "elektronik" demokrasi terimi, en geniş anlamda demokratik süreçlerde politik söylem, politika oluşturma ve hizmet sunumunun daha geniş önemini içerecek şekilde doğrudan vatandaş katılımının dar endişelerinin ötesine geçmektedir (Webster, 1999, s. 118-119). Bu süreçte vatandaşlar giderek artan oranda, politik sürecin katılımcilan değil tüketicileri haline gelmektedir. Oysa demokrasi tarihine bakıldığında, büyük ve elit ekonomik çıkarlar tarafindan vatandaşlar arasındaki kontrolü elde etmek için her zaman bir mücadele görülmüştür. Bu mücadele belki de uzun zamandır bilinçli olarak kabul edilmiş bir sınıf sisteminin uygulandığı Britanya gibi bir ülkede daha belirgin olmuş, diğer ülke geleneklerinde farklı söylemlerle benimsenmiştir. Demokrasilerde, iktidar resmi olarak seçmenlere diğer bir deyişle vatandaşlara verilmiştir ve bu nedenle seçkinler ile halk arasındaki güç dengesi her zaman ezici bir biçimde halkın lehine olmuştur. Oysa gözetim toplumunda vatandaşlar siyaseti siyasal seçkinlere devretmekte, bütün kararları vermek istememekte dolayısıyla bu kararları kendisi adına alacak insanlara oy 
vermektedirler. $\mathrm{Bu}$ da elektronik oylama gibi yollarla elektronik vatandaşlığı ve söylemsel demokrasiyi ortaya çıkarmaktadır.

Görüldüğ̈ gibi gözetim toplumunda demokrasi ve vatandaşlık sorunları ortaya çıkabilmektedir. Bu kapsamda kamusal alanı canlandırmak için özgürleştirici müdahaleye yönelik yeni stratejiler yani "topluluk inşasına" yönelik siyasi faaliyetler, vatandaşlığı ve demokratik katılımı yeniden canlandırmayı planlamaktadır. Çağdaş "kamusal alanı" yeniden şekillendirmede teknolojilerin rolü önemlidir. Bu kapsamda Habermas'n kamusal alan teorisi, vatandaşlık kavramları, demokrasi tipolojileri, teknolojik emperyalizm, coğrafi ütopyalar ve mekânsal determinizm, elektronik demokrasilerin olanakları, riskleri ve kısıtlamaları tartısılmaktadır (Malina,1999, s. 24).

\section{Algoritmik Vatandaşlık}

Vatandaşılı kavramının temelinde yer alan fikir, insanların sınırları geçtikleri, "ait oldukları" yerleri bırakıp girmedikleri yerlere girdiklerinde tehdit altında olmalarıla daha da belirgin hale gelmektedir. Oysa ulus-devlet bir "fikir yapısından" çok daha fazlasıdır. Aynı zamanda bireylerin amaçları için az çok tutarlı bir kurumlar ağıdır. Bu bağlamda ulus devlete üyelik diğer bir deyişle vatandaşlık hak ve görevlerle bağlantilıdır (Torpey, 2018, s. 23-24).

Tarihsel olarak, vatandaş tanımlanabilir bir bireydir. Var olan kimlik bilgilerine dayanarak vatandaş veya yabancı statüsüne atanabilecek bir isim ve kişiliğe sahip birey olarak benzersizdir. Bu referanslar, jus sanguinis (kan hakkı) veya jus solinin (toprak hakkı) politik miraslarından kaynaklanmaktadır (Henriques ve Schuster, 1917, s. 119-131). İstikrarlı hükümetler ve ulusal rejimler himayesinde doğacak kadar şanslı olanlar için, vatandaşlı̆ın doğumla kazanılmasının bahsedildiği gibi iki yolu vardır. Jus soli, toprak hakk1, bir devletin topraklarında doğanlara, kendilerine bakılmaksızın, vatandaşlık verir. Bu hak Amerika'da yaygındır. Daha sıklıkla ise, Jus sanguinis, kan hakk1, ebeveynlerinin sahip olduğu haklara dayanarak bir kişinin vatandaşlı̆̆ın belirler. Kişi doğduğu yerde vatandaşlıktan mahrum bırakılabilir, ancak başka bir yerde edinilebilir (Bridle, 2018, s. 377).

Bir kişi jus sanguinise göre bir vatandaşsa, diğer bir deyişle kan hakkı ile vatandaşlğga sahipse eğer ebeveyni veya eşi bir ülkenin vatandaşıysa, o da o ülkenin bir vatandaşı olmaktadır. Eğer bir kişi jus soliye göre vatandaşsa, bir ülkede doğmuşsa, o ülke vatandaşı olarak doğuştan vatandaşlığa sahip olmaktadır. Vatandaşlğı ispatlayan doğum belgesi, pasaport veya devlet tarafından verilen kimlik kartı, bu yollardan biri veya her ikisinden de elde edilebilir. Böylece doğrulanan bu devlet belgeleri, kişilere resmi vatandaşlık hakk1 verir (Torpey, 2000, s. 88).

Algoritmik vatandaşl1k ise literatürde yeni bir kavramdır. Jus algoritmi, Cheney Lippold tarafından, tanımlama ve sınıflandırma yoluyla kontrol edilen, gözetim devleti tarafından üretilen yeni bir vatandaşlık biçimi tanımlamak için oluşturulmuş bir terimdir (Lippold, 2011, s. 164-181). ABD Ulusal Güvenlik Ajansı (NSA) belgeleri, gözetim programları tartışmalarını devlet gücü ve vatandaşların hakları doğrultusunda daha da alevlendirmiş̧ir. Ancak dijital ağlı bir dünyada vatandaşlık tartışmalanı algoritmik, veri tabanlı bir vatandaşlık versiyonunu yaratmıştır. Lippold, algoritmik vatandaşlı̆̆ın ne anlama geldiği, NSA vatandaşlığı ve ABD vatandaşlığının resmi bir değerlendirme listesini açıklamaktadır. Vatandaşlık, bu durumda, doğrudan internette ürettiğimiz verilere dayanmaktadır. Lippold, bu atamaları "jus algoritmi”" olarak adlandırır, bu nedenle jus sanguinis (aile merkezli vatandaşlık) ve jus solinin (doğum yeri) klasik mirasıyla çelişir. Böylece jus algoritmi "NSA'nın veri yorumlarına göre siyasi hakları dağıtan resmi, devlet tarafından onaylanmış bir vatandaşlık yasasıdır" (Lippold, 2016, s. 1729). Dolayısıyla, "verilerin geçici olarak yorumlanması bağlamında vatandaşlığı ayrıcalıklı kılmak için ulusal kimlik anlamında vatandaşlık işlevsel olarak geçersizdir" (Lippold, 2016, s. 1738). Jus algoritmi açıça bir vatandaşlık şekli iken ayrımc1 asimetriye sahip (ABD dışındaki IP adreslerini, ingilizce dışındaki dilleri ve ABD dışındaki sosyal ağları yabancı olarak işaretler) teorik duruşu ile Arendt'in "haklara sahip olma hakkı" na benzememektedir. Daha ziyade, jus algoritmi yumuşak, dinamik ve süreklidir. Amacı herhangi bir kişinin yabancı olarak algılanmasını ve dolayısıyla ABD devletinin gözetimine maruz kalmasını teorik olarak sağlayan işlevsel bir vatandaşlık statüsü dengesizliği olarak eleştirilmektedir (Lippold, 2016, s. 1736).

Jus algoritmi, algoritmanın hakkı, bir bireyin vatandaşlık durumu hakkında yargılarda bulunmak ve böylece hangi haklara sahip olduğuna ve kendisi üzerinde hangi işlemlere izin verildiğine karar vermek için yazılımın artan kullanımını ifade eder. Bu vatandaşlık biçiminin kökenleri, ABD Ulusal Güvenlik Ajansı'na (NSA) dayanmasına karşın bu gibi testleri uygulayan tek devlet veya denetleyici organ ABD değildir. 
Bununla birlikte, dünyadaki internet trafiğinin çoğunun ABD'den geçtiği bir çağda, tam olarak kimin gözetim altında tutulduğunun tespit edilmesi daha zordur (Bridle, 2018, s. 378).

Özellikle son yıllarda algoritmik vatandaşlık konusu akademik düzeye taşınmış bu konuda algoritmik vatandaşlık ötesinde araştırmalar yapılmıştır. Igor Calzada, "algoritmik uluslar" terimini ortaya atarak, onu şehir-bölge ve tekno-politik bir kavramsal topluluk olarak tanıtmaktadır. Calzada, Avrupa'da siyasi bölgeselleşme süreçleri ile ulus devletlerin yeniden ölçeklendirilmesi arasında değişen dinamikler olduğunu, ulusların fiziki sınırlarının, yaygın ve büyüyen algoritmik, vatansız, likit ve metropol vatandaşlık modellerinde siyasi sınırlar kadar önemli olduğunu ifade etmektedir. Son teknoloji algoritmik yönetişim çerçevelerinin uygulanması ve kullanılması yoluyla dört dinamiğin, jeoekonomi, jeopolitik, jeodemokratik ve jeoteknolojinin algoritmik uluslara doğru geçiş sürecinde etkisini değerlendirmektedir (Calzada, 2018, s.267).

Algoritmik vatandaşlık vatandaşlığın, hakların her zaman sorgulandığı, hesaplandığı ve yeniden yazıldığ1 yeni bir vatandaşlık şeklidir. Jus soli ve Jus sanguinis ya da diğer yollarla herkesin vatandaşlğg olmalıdır. Fakat savaş, göç veya var olan devletlerin çöküşü sonucu milyonlarca vatansız kişi olmasa da, dünya üzerinde epey vatansız insan vardır (http://citizen-ex.com/citizenship). Vatandaşlık sahibi olmak, dünyadaki bir yere bir devlete bağlllı̆̆1 gösterir. Bu devletin, tutuklama özgürlüğü, hapis, işkence veya gözetleme gibi belirli hakları garanti etmesi gerekmektedir. Hannah Arendt, "vatandaşlığın haklara sahip olma hakkı" olduğunu söylemektedir. Bu bağlamda vatandaşlık olmadan hiçbir hak kullanılamaz (Cohen, 1996, s.164-165).

Algoritmik vatandaşlık, doğumda veya karmaşık yasal belgelerle değil, verilerle atanan bir vatandaşlık şeklidir. Diğer bilgisayarlı işlemler gibi, sşık hızında da olabilir ve sürekli tekrar gözden geçirip yeniden hesaplanarak tekrar tekrar olabilir. Tek bir vatandaşlı̆̆ sonsuz sayıda alt vatandaşlığa bölebilir ve zamanla sayıları azaltılabilir ve farklı eyaletlere üye birleşmeleri oluşturabilir. Bu sayısallaştırılmış ortamlarda vatandaşlık ilkeleri, kısmen kullanıcıların yasalaşması, kısmen veri toplama ve analiz etme yoluyla kurulur. Her iki durumda da, belirli teknolojik, politik ve sosyal bağlamlara ihtiyaç vardır. Algoritmik vatandaşlar hareket etmek ve etkileşimde bulunmak için internetin teknik altyapısına güvenmektedir. $\mathrm{Bu}$ ise, kabloların ve cihazların "fiziksel altyapısını" değil, aynı zamanda bu donanımdaki veri akışını düzenleyen ve belirli çevrimiçi etkinliklere izin veren veya vermeyen standartların ve protokollerin "mantıksal altyapisını" içermektedir (Hintz vd., 2017, s. 735). Altyapıya yerleştirilmiş olan kod, algoritmik vatandaşlık firsatlarını ve internet standartlarını geliştiren ve veri akışını düzenleyen kurumları geliştirebilir veya azaltabilir. Ayrıca, iletişim, işlemler, hizmetler ve bilgi için çok sayıda kurumsal platformlara artan bir bağımlılıkla, özel ve ticari olarak da yönlendirilmektedir. Algoritmik vatandaşlar, sadece yasallık ve anayasal haklarla değil, aynı zamanda ticari bağlamda da sinırlanmaktadır (Leistert, 2015, s. 36).

Farklı türlerdeki ve alt yapı seviyelerindeki bu karmaşık ortamda, algoritmik vatandaşlık, internet kullanıcılarının ifade özgürlüğ̈̈ ve mahremiyet gibi temel haklarının yeterli şekilde korunmasını gerektirmektedir. Protokoller, standartlar ve çevrimiçi platformların (kullanılan algoritmaların) hizmet şartları, bu politika ortamının önemli bir parçasını oluşturmakta, ulusal yasalar ve yönetmelikler bölgesel politikalarla birlikte gerekli temel taşları sağlamaya devam etmektedir. Güvenli çevrimiçi etkileşimler için destekleyici bir yasal ve düzenleyici çerçeve algoritmik vatandaşlık için önemli bir koşuldur (Hintz vd., 2017, s. 735).

Algoritmik vatandaşlık tipik olarak ulus-devlete ait olma statüleri ve onunla birlikte gelen hak ve sorumluluklarla değil daha ziyade insanların eylemleriyle tanımlanır. Vatandaşların toplumdaki rolünü yarattp yerine getirmelerini ifade eder. Isin ve Ruppert bunu, "bireyin kendisini siber uzaya sokması" olarak tanımlamaktadır (Isin ve Ruppert, 2015, s. 43). Tipkı vatandaşların geleneksel olarak insan hakları ve medeni haklar talep ederek devletle ilişkilerini sürdürdükleri gibi algoritmik vatandaşlıkta "hak iddiaları" dijital ortama taşınmaktadır (Isin ve Ruppert, 2015, s. 4).

Dijital ortamdaki bu vatandaşlığın aktif inşası geniş kapsamlıdır. Genel olarak dijital faaliyetlerin ve algoritmik vatandaşlğı̆n demokratikleştirici etkisi önemlidir. Gelinen noktada gözetim kültürü, yetkilileri izleyen ve yanlış yaptıklarını açıklayan vatandaşların "gözetleme" uygulamalarını desteklemektedir. Bu bağlamda dijital, mobil ve sosyal medya ilişkilerinin etkili bir şekilde kullanılması, topluma demokratik katılımı artırabilir ve yenilik, sosyal değişim ve kamu yararı yaratabilir. Bu şekilde anlaşılan aktif dijital uygulamalar ve algoritmik vatandaşlık, vatandaşın güçlendirilmesi anlamına gelmektedir (Hintz vd., 2017, s.731-732). 
Dijital aracılı vatandaşlık konusundaki ilginç bir güncel deneyim Estonya'da uygulanmıştır. Estonya, 1990'ların ortasindan bu yana, en kablolu ülke olma yolunda ilerlemektedir. 1991 yllinda Estonya, Sovyetler Birliği’nden kopup egemen küçük bir devlet olarak bağımsızlığını geri kazanmıştır (Puura vd., 2017, s. 7-25). 2000 yllında hükümet internet erişiminin bir insan hakkı olduğunu ilan etmiștir. 2014 y1lında ülke dışından insanlara elektronik ikamet sunarak sınırsız bir ülke fikrine doğru giden ilk ülke olmuştur. Estonya dijital toplumunun faydalarını sunan bu "e-ikamet" programı ile sağlanan hizmetler, banka hesabı açma, belgeleri dijital olarak imzalama, bir iş kurma, çevrimiçi vergi ödeme kısacası, fiili, fiziksel ikamet durumu dışında, kendi vatandaşlarına sunulan devlet hizmetlerinin çoğu neredeyse herkese sunulmaktadır. E-Estonya (2016), Estonya hükümetinin, elektronik çözümler kullanarak vatandaşın devletle etkileşimlerini kolaylaştırmak için (blockchain) blok zinciri teknolojisine dayalı bir hareketini ifade etmektedir. Böylelikle e-oylama, e-vergi kurulu, e-ticaret, e-bankacilık, e-bilet, e-okul, e-üniversite ve e-yönetişim akademisi oluşturulmuştur. Bu sayede Estonya, vatandaşları için kimlik doğrulama, elektronik oylama sistemleri ve dijital para birimi için e-kimlik vermede blockchain teknolojisinin kullanımında lider olmuştur (Calzada, 2018, s. 275).

Günümüzde Estonya dünyadaki internet altyapısına, bilgi teknolojisi becerilerine ve çevrimiçi oylama, doğrudan demokrasi ve elektronik sağlık kayıtları gibi dijital toplum yeniliklerine yatırım yapma konusunda öncü çalışmalarıyla dikkat çekmektedir. Aslında, Estonya, çağdaş yazılım platformları modelinde bir vatandaşlık hizmeti sunarak, fiziksel bölgesinin alt katmanından bir dizi devlet eylemini sınırlandırmıştır. Gelinen noktada Estonya, Avrupa'daki en büyük vatansız nüfuslardan birine sahiptir. Baltık komşularıyla ortak olarak, nüfusun önemli bir kısmı Sovyetler Birliğ̣’nin çöküşünden sonra kabul edilen vatandaşlığa kabul yasaları nedeniyle vatansız kalmıştır. Bu yasalar, Rusya'dan veya Sovyetler Birliği’ndeki herhangi bir yerdeki etnik grup üyelerinin, yeni bağımsız cumhuriyetlerdeki vatandaşlıkları için yeniden başvurmalarını gerektirmektedir. Siyasal nedenler, bürokrasi, tarih, aile ya da diğer sebeplerle çoğu insan vatandaşlığa geçememiş ve böylelikle binlerce "vatandaş olmayan" kişi ortaya çıkmıştır. E-ikamet gibi teknolojik yeniliklerin, yeniden yapılandırılmış vatandaşlık sistemlerinden yararlanacak olanlara fayda sağlayıp sağlayamayacağı noktasında sorular olsa da diğer dijital ürünler, yalnızca birinci sınıf pasaportları, bilgiye birinci sınıf erişimi, ayrıcalıkları ve firsatları olanların hareket alanını güçlendirmektedir (Bridle, 2018, s. 379-380).

Gözetim toplumunun ortaya çıkardığ1 yeni uygulamalar ve vatandaşlık modelleri örneklerine bakıldığında Estonya'nın e-ikametgâh uygulamaları bunlardan yalnızca bir tanesidir. Brexit oyu, İngiltere'nin vatandaşlık noktasında seçim hakkını göstermektedir. Bu bağlamda İngiltere, başından bu yana Birlik aleyhine takındığı olumsuz tutumlar doğrultusunda bir takım girişimlerde bulunmuştur. $A B$ üyeliğinin sona ermesi yönünde 1975'te bir referanduma gitmiş, seçmenlerin \% 67'si üyeliğin devam etmesi yönünde oy kullanmıştır. 2016'da gerçekleştirilen referandumda, seçmenlerin \% 52'si Avrupa Birliği'nden çıkılması yönünde oy kullanmıştır. Bu referandumlar Brexit olarak adlandırılmakta ve gelinen noktada vatandaşlığın demokratik bir tercih olduğunu vurgulamaktadır. Avrupa'daki ulus-devlet bölümleri, İskoç ve Katalan referandumları algoritmik uygulamalara dair diğer örneklerdir.

Dijital vatandaşlık, algoritmik vatandaşlık gibi gelişmelerin yaşandığı bir dönemde ilk uzay ülkesi olma amacıyla kurulan 2017 yılının sonlarında dünyadan resmen ayrllıp uzaya yerleşen Asgardia bu bağlamda değerlendirilmesi gereken diğer bir örnek olmuştur. Deneysel bir çalışma olan Asgardia projesi NASA tarafından yönetilmektedir. Asgardia projesinin planlandığı 2017 yllında internet üzerinden çevrimiçi vatandaşlık başvurusu alan proje, gelinen noktada aldığı başvurularla 1.059.208 nüfusa sahiptir. Ülke ilk devlet başkanını seçmiştir. Igor Ashurbeyli’nin başkanı olduğu uzay ülkesinin, tıpkı geleneksel ulus devlet modellerinde olduğu gibi seçili vekillerden oluşan bir meclisi ve üyeleri tarafindan oylama ile kabul edilen bir anayasası bulunmaktadır. Birleşmiş Milletler'e de üye olmayı hedefleyen Asgardia'nın bayrağı ve milli marşı da bulunmaktadır. Asgardia için internet sitesinden kayıt olmak ücretsiz olmakla birlikte meclise seçilebilmek gibi vatandaşlık ayrıcalıklarından faydalanabilmek için üyelerden 100 Euro miktarında yıllık ücret istenmektedir (www.asgardia.space/en/).

Ortaya çıkan yeni vatandaşlık biçimi olarak algoritmik vatandaşlıkta, bilgisayar algoritmaları, dijital dünyada "kim olduğumuza" karar vermek için dijital aktivite gibi verileri kullanmaktadır. Hükümetler ve özel firmalar bu verileri kişinin durumu, kimliği ve hakları ile ilgili soruları belirlemek için kullanmaktadır. Örneğin, NSA'nın "algoritmik olarak yabancıları" hedefleyen PRISM Gözetim Programı veya ABD İç Güvenlik Bakanlı̆̆ı’nın arama tabanlı göçmenlerle ilgili veri toplama planı bu şekildedir (Emerging Technologies And The Future Of Citizenship). 
Gelinen nokta yeni nesil teknolojinin, ademi merkeziyetçi jeopolitiğin geleceğini nasıl şekillendirdiğinin yeniden düşünülmesine yol açmaktadır. Bu bağlamda uluslar farklı bir algoritmik alanda kurulabilir mi? Jeo ekonomik, jeopolitik, jeo demokratik ve jeo teknolojik dinamikleri giderek yayginlaşan büyük verilerin harmanlanmasıyla tekno-politik şehir bölgeleri nasıl yeniden düşünülebilir? soruları bu gelişmelerle birlikte ele alınan konulardır. Veri bilimi ve yapay zekânın, demokratik ve politik karar alma süreçlerini nasıl zenginleştirebileceği, veri şeffafluğı ve yönetişim planlarının, paydaşların nasıl olacağı gibi önemli hususlar dikkatle değerlendirilmelidir. Algoritmik bir ulus, bu şekilde dağttlabilecek devlet kimlikleriyle mi oluşacak? Algoritmik vatandaşların doğdukları kimliğinden ziyade tercih ettikleri kimliği almalarını engelleyen şey nedir? Ulus inşa süreci, algoritmik uluslar adı verilen yeni bir paradigmaya doğru ilerliyor mu? (Calzada, 2018, s. 283-284) gibi karmassık sorular cevap bekleyen önemli konulardır.

Şifrelenmiş şekilde veri yönetimi sağlayan dağınık yapıda bir veri tabanı sistemi olarak adlandırlan Blockchain (blok zinciri) uygulamaları ve yeni devlet hizmetleri yaratma konusundaki mevcut girişimlere bakıldığı zaman önemli dönüşümler görülmektedir. E-Estonya ve Asgardia örneklerinde bölgesel olmayan siyasi üyelik biçimleri ortaya çıkmakta ve bilinen şekliyle kalıcı bir nüfusa, fiziksel bir bölgeye ve merkezi bir hükümete sahip olması gereken bir tüzel kişilik olarak "devletin” tanımı farklılaşmaktadır. Blockchain teknolojileri, ulus devletin ötesinde yeni siyasi üyelik biçimlerinin temelini oluşturma ve böylelikle "vatandaşlık" ve "egemenlik" kavramlarını sorgulamaktadır. Gelinen noktada farklı uygulamalarıyla "Algoritmik kimlik" vatandaşlı̆ı̆ı durumunu ve anlamını yeniden tanımlamak noktasında gelişmeye devam etmektedir.

\section{Sonuç ve Değerlendirme}

21. Yüzyıl toplumsal yapısı artık yeni nesil bilgi ve iletişim teknolojileri ile birlikte çok yoğun şekilde gözetimin gerçekleştiği bir gözetim toplumudur. Gözetim teknolojileri Orwell'in 1984'ünde olduğu gibi totaliter özellikleri barındırmakla birlikte günümüzde suç ve suçlularla mücadele diğer bir deyişle güvenlik gerekçeleriyle devletler açısından önemli araçlar olarak kullanılmaktadır. Gözetim teknolojilerinin yaygınlaşmasıyla birlikte ortaya çıkan gözetim toplumu riskleri, tehditleri ve firsatlarıla toplumsal yapıda bir takım dönüşümlere yol açmıştır. Özellikle siyasal alanda, devlet yapısında ve vatandaşlık modellerinde inovatif yenilikler oluşturmuştur. Habermas'ta gelişen ve büyüyen kamusal alan/mekân gelenekselden siber uzaya taşınmıştır. Böylelikle oy verme, propaganda yapma, siyasal tutum ve faaliyetleri ölçme vs. gibi siyasal aktiviteler ve tutumlar da bu dijital alanda gerçekleştirilmektedir. Bu yeni kamusal mekâna daha hızlı, daha ekonomik ve daha etkili olma gibi özellikleri ile kolaylıkla entegre olunmuştur. Gözetim toplumu, demokrasinin en önemli bileşeni olan demosu güçlendirmiş ve katıllımcllı̆̆ pekiştirmiştir. Öte taraftan gözetim toplumunun siyasette yaratmış olduğu bu pozitif fark, sürekli gözetim yoluyla demokrasinin temel değeri olan özgürlükler üzerinde kısıtlayıcı olmuştur. Gözetim toplumu oluşturduğu bu fayda ve maliyetler doğrultusunda gelişmeye ve yoğunlaşmaya devam etmektedir.

Aynı zamanda bu yeni toplumsal yapı oluşturduğu yeni algoritmik vatandaşlık modeli ile vatansızlık fenomenini sınırlandırmaktadır. İnternet üzerinde veri temelli gelişen bu vatandaşlık modeli günümüzde farklı uygulama ve örnekleri ile tercih özgürlüğü bağlamında gelişmeye devam etmektedir. Günümüzde EEstonya, Brexit, Asgardia, NSA'nın PRISM Gözetim Programı uygulamaları yeni nesil vatandaşlık uygulamaları olarak dikkat çekmekte, Çin'in farklı yapay zeka uygulamaları ile sürekli gözetim altında tuttuğu vatandaşları puanladığı sistem daha farklı boyutta dijital vatandaşlık uygulamaları oluşacağının sinyallerini vermektedir.

Gelinen noktada algoritmik vatandaşlık geleneksel vatandaşlığın bir alternatifi olarak değerlendirilmektedir. Katılımcı, müzakereci, radikal, ekonomik, seçkinci vs. çağdaş demokrasi kuramları da gözetim toplumun oluşturduğu bu yeni özellikler ve vatandaşlık modelleri ekseninde kendisine yeni demokrasi modelleri eklemlemektedir. Günümüzde algoritmik vatandaşlık algoritmik demokrasi bağlamında gelişmeye devam edecektir. Sonuç olarak, gözetim toplumunda küçük devletsiz, metropol ve vatansız, bir tür algoritmik vatandaşlık modellerinin hızla geliştiği gerçeğine rağmen, daha somut güvenlik ve koruma sağlaması dolayısıyla sınırlar ve ulus devlet modellerinin de hala oldukça önemli olduğu söylenebilir. 


\section{Etik Beyan}

“Gözetim Toplumunun Siyaset, Devlet ve Demokraside Yansımaları: Algoritmik Vatandaşlık Odağında Bir Değerlendirme" başlıklı çalışmanın yazım sürecinde bilimsel, etik ve alıntı kurallarına uyulmuş; toplanan veriler üzerinde herhangi bir tahrifat yapılmamış ve bu çalışma herhangi başka bir akademik yayın ortamına değerlendirme için gönderilmemiştir.

\section{Kaynakça}

Arendt, H. (1949). The rights of man: What are they? Modern Review, 3, 24-37.

Asgardia (2018). The space kingdom, www.asgardia.space/en/ (E.T. 11.02.2019)

Akos R.T. (2017). The off-label use of consumer credit ratings, Historical Social Research, 43(1), 52-76.

https://www.sitra.fi/en/articles/algorithmic-democracy-technological-transformation-lead-post-truth-era/(E.T. 11.02.2019)

http://citizen-ex.com/citizenship (E.T. 10.02.2019)

Berelson, B. (1952). Democratic theory and public opinion. Public Opinion Quarterly, 16, 313-330.

Bernstein, R. J. (2018). Why read hannah arendt now? Cambridge: Polity.

Bridle, J. (2016). Algorithmic citizenship, digital statelessness, GeoHumanities, 2(2), 377-381.

Calzada I. (2018). "Algorithmic nations": seeing like a city-regional and techno-political conceptual assemblage, Regional Studies, Regional Science, 5(1), 267-289.

Cohen, J. (1996). "Rights and citizenship in hannah arendt. dilemmas of arendtian republicanism," Constellations, 3(2), $164-189$

Couldry, N. (2017). Surveillance-democracy, Journal of Information Technology Politics, 14(2), 182-188.

Davies, S. (1996). Big brother: Britain's web of surveillance and the new technological order, London: Pan Books.

Dewey, J. (1993). The political writings. D. Morris and I. Shapiro (Eds.). Indianapolis: Hackett.

Gandy, O. (1994). The Panoptic society, Boulder, CO: Westview.

Giddens A. (1985). The nation-state and violence volume two of a contemporary critique of historical materialism, Polity Press, Cambridge.

Gramsci, A. (1984). "Americanism and Fordism”, in Q. Hoare and G. Nowell Smith (trans.) Selection from the Prison Notebooks . New York: International Publishers.

Hague B. N. ve Loader B. D. (Edited by) (1999). Digital democracy discourse and decision making in the information age, First Published by Routledge.

Harrison, T. M. ve Falvey L. (2001). Democracy and new communication technologies, Annals of the International Communication Association, 25(1), 1-43.

Henriques, H. S. Q. ve Schuster, E. J. (1917). “Jus soli" or “jus sanguinis”? Problems Of The War, 3, 119-131.

Hintz, A., Dencik, L., ve Wahl-Jorgensen K. (2017). Digital citizenship and surveillance society, International Journal of Communication 11, 731-739.

Howard P. N. (2010). The digital origins of dictatorship and democracy: information technology and political Islam, Oxford University Press.

Isın, E., ve Ruppert, E. (2015). Becoming digital citizens. Lanham, MD: Rowman and Littlefield.

Lefebvre, H. (1974/1991). The production of space. Trans. D. Nicholson- Smith. Oxford: Blackwell.

Leistert, O. (2015). The revolution will not be liked: on the systematic constraints of corporate social media platforms for protest. In L. Dencik and O. Leistert (Eds.), Critical perspectives on social media and protest: Between control and emancipation (pp. 35-52). Lanham, MD: Rowman and Littlefield.

Lippold, C. J. (2011). A new algorithmic identity: Soft biopolitics and the modulation of control. Theory, Culture, Society, 28(6) 164-181.

Lippold, C. J. (2016). Jus algoritmi: how the national security agency remade citizenship, International Journal of Communication, 10 (2016), 1721-1742. http://ijoc.org/index.php/ijoc/article/view/4480/1618

Lutz, B. ve Toit, P. D. (2014). Defining democracy in a digital age: political support on social media, Palgrave Macmillan.

Lyon, D. (2006). Theorizing surveillance the panopticon and beyond, Willan Publishing.

Lyon, D. (1994). The electronic eye: the rise of the surveillance society, Cambridge: Polity Press.

Malina, A. (1999). Perspectives on citizen democratisation and alienation in the virtual public sphere. (Edited By) Hague Barry N. And Loader Brian D. Digital democracy discourse and decision making in the information age. USA: Routledge.

Chorzempa, M., Triolo, P. ve Sacks, S. (2018). China's social credit system: a mark of progress or a threat to privacy? Peterson Institute for International Economics, Policy Brief, 18-143.

Ogura, T. (2006). Electronic government and surveillance-oriented society, Edited By, Lyon, David, Theorizing Surveillance The Panopticon And Beyond, Willan Publishing.

O’harrow, R. (2005). No place to bide, A Division of Simon and Schuster, Inc.

Orwell, G. (1949). 1984. Penguin Books. 
O’toole, J. (1990). Information and power: social and political consequences of advanced, Tele/Computing Technology, The Annual Review-1990, 211-249. Queenstown, MD: Institute for Information Studies.

Rodriguez-Posé, A. (2018). The revenge of the places that don't matter (and what to do about it). Cambridge Journal of Regions, Economy And Society, 11(1), 189-209.

Puura, A., S1lm, S., ve Ahas, R. (2017). The relationship between social networks and spatial mobility: a mobilephone based study in Estonia, Journal Of Urban Technology, 25(2), 7-25.

Schwartz, P. M. (1999). Privacy and democracy in cyberspace, 52 Vand. L. Rev. 1607.

Síthigh, D. ve Siems, M. (2019). The chinese social credit system: a model for other countries? European University Institute Department of Law, EUI Working Paper LAW 2019/01

Tewksbury, D. ve Rittenberg, J. (2012). News on the internet information and citizenship in the 21st century, Oxford University Press.

Torpey, J. (2018). The invention of the passport surveillance, citizenship and the state, Cambridge University Press.

Webster, C. ve William, R. (1999). Closed circuit television and information age policy processes, (Edited by) Hague Barry N. and Loader Brian D. Digital Democracy Discourse and Decision Making in the Information Age, First published by Routledge.

Zuboff, S. (2015). Big other: surveillance capitalism and the prospects of an information civilization. Journal of Information Technology, 30, 75-89.

\section{EXTENDED ABSTRACT}

The scope of the surveillance, which was under the theme of commercial, social, cultural, political and security in our age, clearly emphasizes that there has been a period that can be called as, surveillance society İçinde. The surveillance society forms an electronic surveillance system with the widespread use of the Internet. Tedir Surveillance studies 11 continue to attract attention and spread rapidly in the academic field together with the rapid developments in governance and new technologies.

While the history of surveillance practices is almost as old as the history of mankind, it has taken some special forms in our age. Computer-based new technologies are being implemented with decisiveness in surveillance processes. In this area, Foucault's Discipline and Punishment encouraged new approaches to understanding surveillance. Outside of Foucault, the names such as Frederick Taylor, Anthony Giddens, Antonio Gramsci, and George Orwell have overseen the phenomenon of surveillance.

Through the Internet, the collection of data on social and public life, and the continuous automatic monitoring on which data collection is based, contradicts democratic institutions and values. Issues such as sense of identity, right to life, human rights, privacy are more important than ever. Political power, social control, freedom and democracy are the most important cornerstones. The freedom and security equation that has been discussed since Thomas Hobbes is expanding in favor of security in our age. Hence, it has been legitimized in terms of states in terms of surveillance, terrorism and combating crime.

Surveillance society thus concentrates on the political structure, state and democracy. One of the issues that this model of society has changed is on the structures of citizenship. In general, the right to citizenship is the 1 right to have rights 1 in the words of Arendt. Without this right it is not possible for the individual to use his rights and freedoms. In the context of modern nation-states, citizenship is a protective element in this direction.

Stephen Castells calls this century "Age of Migration". As a result of wars, internal turmoil in the countries, economic and family reasons, people leave their countries voluntarily or necessarily. This constitutes a dimension of algorithmic citizenship as a model of citizenship that is created by the surveillance society. According to jus soli (right of land) and jus sanguinis (right to blood), metropolitan citizenship, stateless citizenship, liquid citizenship or more people prefer the right of choice jus algorithm is raised.

The Jus algorithm is an official, state-approved, citizenship law that distributes political rights according to the data interpretations of the US National Security Agency (NSA). Algorithmic citizenship is a form of citizenship that is assigned by data, not by birth or by complex legal documents. Like other computerized processes, it can also be at the speed of light, and can be re-calculated and recalculated continuously.

The active construction of this citizenship in the digital environment is extensive. In general, the democratizing effect of digital activities and algorithmic citizenship is important. The surveillance culture supports the $1 \mathrm{k}$ surveillance ini practices of the citizens who monitor the state authorities and explain that they have done wrong. In this context, effective use of digital, mobile and social media relations can increase democratic participation in society and create innovation, social change and the public interest. 
Active digital applications and algorithmic citizenship, understood in this way, can mean citizen empowerment.

Algorithmic citizenship applications can be exemplary. According to this, the nation-state departments in Europe, the Scottish and Catalan referendums, and the Brexit vote emphasize that citizenship is a democratic choice. On the other hand, the space state citizenship created by the Asgardia project and the steps taken by Estonia in the context of E-resident practices are other examples of algorithmic applications. Algorithmic citizenship is considered as an alternative to traditional citizenship. In this context, the participant, the negotiator, the radical, the economic, the elitist, etc. The contemporary theories of democracy may also combine a new model of democracy with algorithmic democracy in the axis of these new features and models of citizenship created by the surveillance society. 